\title{
Spontaneous pneumothorax as indicator for Birt-Hogg-Dubé syndrome in paediatric patients
}

\author{
Paul C Johannesma', Ben EEM van den Borne², Johannes JP Gille ${ }^{3}$, Ad F Nagelkerke $^{4}$, \\ JanHein TM van Waesberghe ${ }^{5}$, Marinus A Paul ${ }^{6}$, R Jeroen A van Moorselaar ${ }^{7}$, Fred H Menko ${ }^{8}$ \\ and Pieter E Postmus ${ }^{1 *}$
}

\begin{abstract}
Background: Birt-Hogg-Dubé syndrome (BHD) is a rare autosomal dominantly inherited disorder caused by germline mutations in the folliculin (FLCN) gene. Clinical manifestations of BHD include skin fibrofolliculomas, renal cell cancer, lung cysts and (recurrent) spontaneous pneumothorax (SP). All clinical manifestations usually present in adults $>20$ years of age.

Case presentations: Two non-related patients with (recurrent) pneumothorax starting at age 14 accompanied by multiple basal lung cysts on thoracic CT underwent FLCN germline mutation analysis. A pathogenic FLCN mutation was found in both patients confirming suspected BHD. The family history was negative for spontaneous pneumothorax in both families.
\end{abstract}

Conclusion: Although childhood occurrence of SP in BHD is rare, these two cases illustrate that BHD should be considered as cause of SP in children.

Keywords: Birt-Hogg-Dubé syndrome, BHD, Folliculin, FLCN, Spontaneous pneumothorax, Renal cell cancer, Fibrofolliculomas

\section{Background}

Birt-Hogg-Dubé syndrome (BHD) is a rare tumour predisposition syndrome first described in 1977 [1]. The syndrome is characterized by skin fibrofolliculomas, lung cysts, (recurrent) spontaneous pneumothorax (SP) and renal cell cancer. The underlying cause is a germline mutation in the folliculin (FLCN) gene located on chromosome 17p11.2. Clinical manifestation usually appears after the age of 20 years. We here present two cases of BHD with episodes of recurrent pneumothorax of which the first episode occurred at the age of 14 years.

\section{Case presentation}

\section{Case 1}

A 14-year-old Caucasian boy, without any medical problems in the past, non-smoker, was admitted to the Emergency Department due to shortness of breath and right-

\footnotetext{
*Correspondence: pe.postmus@vumc.nl

'Department of Pulmonary Diseases, VU University Medical Center, PO Box 7057, 1007, MB Amsterdam, The Netherlands

Full list of author information is available at the end of the article
}

sided chest pain which increased when bending over. In general, he looked healthy and he had no fever. Breath sounds over the right hemithorax were reduced. Routine laboratory tests showed no abnormalities. Chest X-ray showed a right-sided pneumothorax with a complete collapse of the right lung. After drainage by catheter, thoracoscopic pleurodesis was performed. Approximately 8 months later right-sided pneumothorax recurred and was treated by partial right-sided pleurectomy. In the subsequent two years the patient had another two recurrences, both treated by catheter drainage. Because of the recurrent episodes of pneumothorax a CT of his chest was performed, which showed multiple cysts below the level of the carina in the lung parenchyma adjacent to the visceral pleura (subpleurally), predominantly on the right side. (CT-thorax, Figure 1a and b) BHD was suspected and genetic testing confirmed a pathogenic splice-site mutation in the gene (c.1177-5_1177-3delCTC). Skin fibrofolliculomas and renal abnormalities were absent in this patient. Subsequently other family members were counselled by the clinical geneticist. Three family members were also affected. 

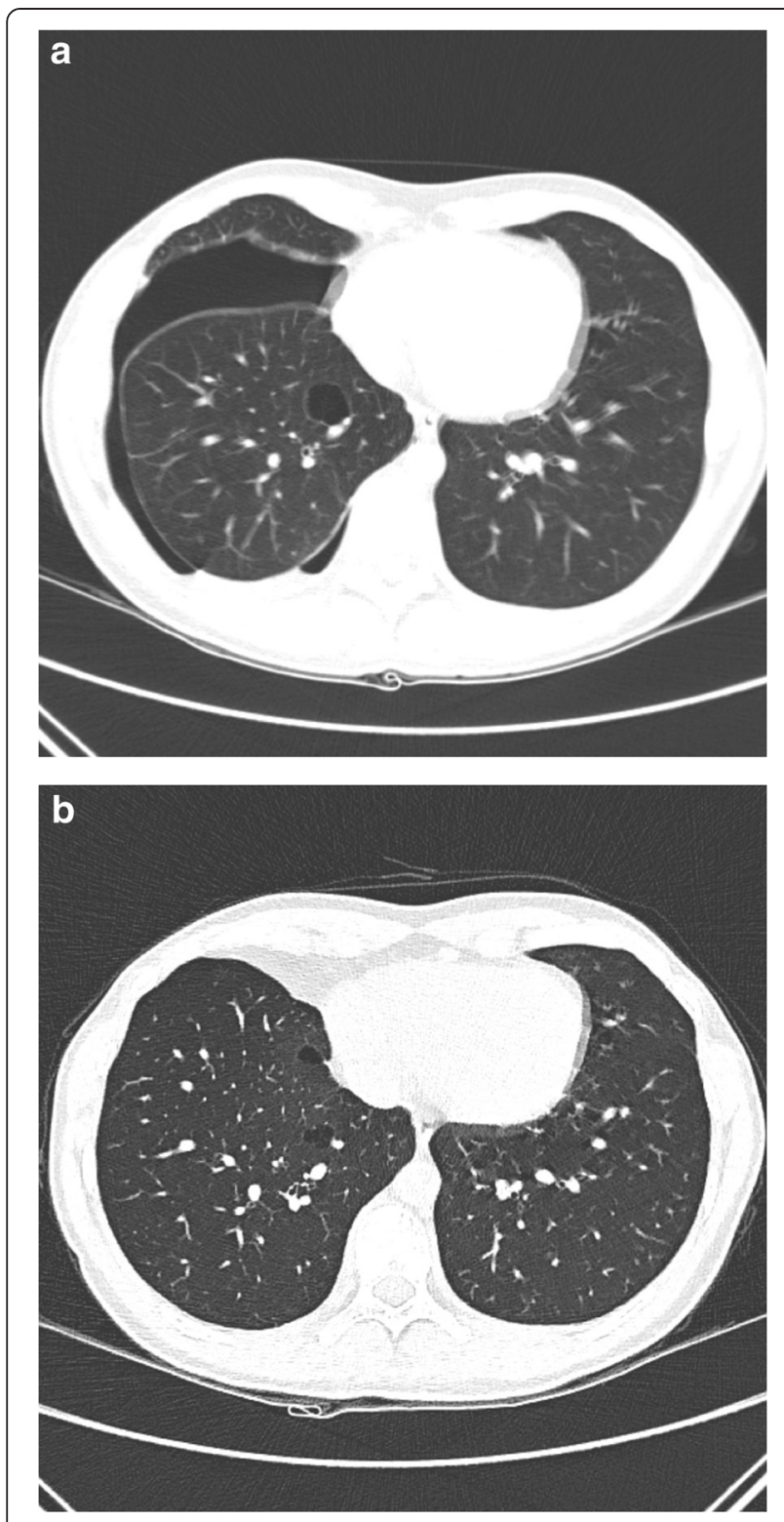

Figure 1 Thoracic CT of case 1. a. CT shows a pneumothorax with a intraparenchymal located cyst with small septa. b. Shows multiple cysts in the lower lobes (under the carina), in the same patient after treatment of the pneumothorax.

The family history was negative for renal cell cancer (RCC) or (recurrent) episodes of pneumothorax.

\section{Case 2}

A 19-year-old Caucasian male presented at the Emergency Department due to recurrent right-sided pneumothorax. The first episode had occurred at age 14 and was treated by video-assisted-thoracoscopic surgery (VATS). A chest CT now revealed a completely collapsed right lung with multiple air-filled structures described as bullae at the ventro-cranial side of the right lower lobe. An uncomplicated VATS procedure was performed. Although the thoracic CT showed multiple cysts mainly in the basal parts of the right lung, none were seen at operation. Total pleurectomy was performed. Two years later the patient was referred to our center for evaluation for BHD as this syndrome had been diagnosed in several family members. A chest CT now showed several small cysts in both lungs in the parenchyma and larger cysts resembling 'bullae' mainly in the right lung (CT-thorax, Figure 2a and b). Genetic testing confirmed a pathogenic splice-site mutation (c.1301-7_1304del;1323delCinsGA) of the FLCN gene., which confirmed the diagnosis of BHD. Skin fibrofolliculomas and renal abnormalities were absent in
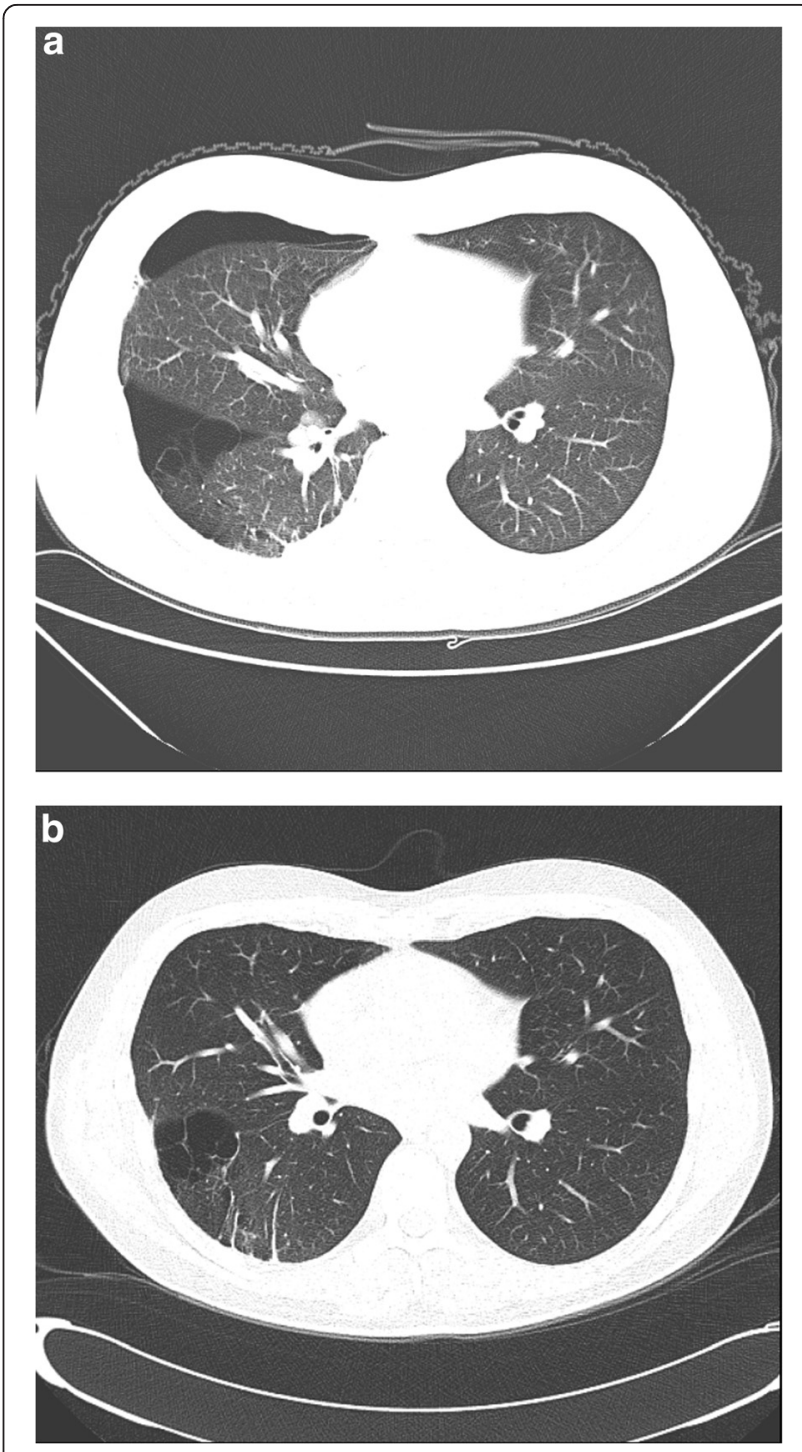

Figure $\mathbf{2}$ Thoracic CT of case 2. a. CT image of pneumothorax with a cluster of lung cysts in the right lower lobe. b. Shows a lung cyst located subpleurally in the right lower lobe, abutting the main fissure as shown after resolving of the pneumothorax. 
this patient. Family members had skin fibrofolliculomas, but no RCC or pneumothorax had been observed.

\section{Conclusions}

We report here two paediatric patients with recurrent spontaneous pneumothorax as a manifestation of the Birt-Hogg-Dubé syndrome (BHD). Lung cysts were seen in both patients, predominantly located below the level of the carina, located subpleurally in the lung parenchyma. The location of these cysts is typical for BHD.

In general, the incidence of paediatric primary and secondary SP is approximately 4 per 100.000 males and 1.1. per 100.000 females per year, which is much less common than in adulthood $[2,3]$. The mean age at presentation of PSP in paediatric cases is between 13.8-15.9 years and occurs commonly in tall, thin males [4]. A specific racial/ ethnic predominance has not been described in literature [2]. The underlying cause in spontaneous SP in adulthood is often unknown in the primary form, but secondary SP may be due to an inflammatory or connective tissue disease, infection, malignancy, foreign body aspiration or congenital malformation [5]. Subpleural bullae, mainly in the apex of the lung, are found in 76-100 per cent of adult PSP patients during VATS and thoracotomy [6]. Among non-smokers with a history of PSP, 81 per cent have bullae [7]. The general underlying mechanism of PSP in childhood seems to be connective tissue changes, which predispose to spontaneous leaking of air from the airways into the pleural space. Several case series suggest a relation between subpleural blebs/bullae and the occurrence of SP $[2,8]$. The incidence of blebs and bullae detected on CT in children with SP is between $45 \%$ and $100 \%$ [9]. The clinical significance of these blebs and bullae remains unclear [4].

SP in children is often diagnosed based on medical history and physical examination, confirmed by chest radiography. The additional value of chest $\mathrm{CT}$ is unclear. In the British Thoracic Society (BTS) guidelines a CT of the chest is indicated when chest radiography is negative of clinical signs for SP or for determining appropriate management strategies. Because blebs, bullae and cysts are only visible on $\mathrm{CT}$, which is performed in a minority of cases, the diagnosis BHD is likely to be missed.

Adult literature reports a recurrence rate in primary SP of approximately 30 percent, with a range of 16 to 52 percent [10]. In children a recurrence rate up to 61 percent has been reported and seems to be higher compared to the adult data [11]. A smaller study by Ouanes-Berbes et al. reported a 19\% overall recurrence rate over 7 year follow-up in a young adult cohort, with a 72 percent incidence of bullae [12].

In adults, multiple lung cysts are associated with Birt-Hogg-Dubé syndrome, with a basal rather than apical distribution. The literature on the incidence of BHD syndrome in adults with PSP is very limited. Ren and colleagues found a prevalence of $9.8 \%$ in 102 apparently adult SP patients [13]. In a pilot study among 40 apparently primary SP patients we found a pathogenic FLCN mutation in $3(7.5 \%)$ patients [14].

Previously, SP has been reported twice in paediatric BHD patients both confirmed by the demonstration of a pathogenic $F L C N$-mutation. The first patient had one episode of SP at age of 7 years. Chest CT was not performed. The second patient at age of 16 years, with a positive family history for SP, had in total 6 episodes of SP on both sides with, multiple basally located cysts on chest CT $[15,16]$. The youngest BHD patient with pneumothorax we observed was an 18 year old woman with two episodes of right sided spontaneous pneumothorax with lung cysts [17].

BHD [OMIM no. 135150] is a rare autosomal dominant inherited disorder caused by germline mutations in the $(F L C N)$ gene located on chromosome 17p11.2. The BHD gene encodes for the protein folliculin which is expressed in skin, kidney and nephrons and type 1 pulmonary alveolar epithelial cells. The function of folliculin has not been fully clarified $[18,19]$. Clinically BHD is characterized by skin fibrofolliculomas, a 50-fold increased risk for development of (recurrent) SP, multiple lung cysts predominantly in the basal parts of the lung, renal cysts and renal cancer from the age of $20[17,18]$. Patients are advised to undergo lifelong surveillance, preferably by periodic renal MRI or ultrasound. Because the clinical expression can vary and is age-dependent, BHD syndrome in patients who present with pneumothorax cannot be excluded when no renal abnormalities or skin lesions are found [20]. The differential diagnosis of patients with multiple lung cysts include emphysema, cystic bronchiectasis, honeycomb change, cavitated infective nodules, pulmonary Langerhans cell histiocytosis (LCH), lymphangioleiomyomatosis (LAM), lymphocytic interstitial pneumonia (LIP), follicular bronchiolitis, amyloidosis, light chain deposition disease (LCDD) and Birt-Hogg-Dubé (BHD) syndrome [21]. The cystic pattern in BHD differs from that observed in other lung diseases; In BHD multiple thin-walled pulmonary cysts of various sizes are observed, predominately distributed to the lower medial and subpleural regions of the lung with cysts abutting or including the proximal portion of the lower pulmonary veins or arteries [22-24].

Treatment of SP in children does not differ from that in adults and depends on size and underlying cause. Both BTS and American College of Chest Physicians (ACCP) have published different recommendations for treatment of primary SP in adults as well paediatric patients. Multiple studies in adult literature advocate aspiration as a first treatment option in PSP. For secondary SP or recurrent SP the ACCP and BTS recommend tube thoracostomy and surgical recurrence prevention $[2,25]$. Whether 
treatment of pneumothorax in BHD patients needs to be more aggressive than in idiopathic SP is still under debate [18].

In conclusion we report here two cases of Birt-HoggDubé syndrome in children with recurrent pneumothorax. As SP in the paediatric population is relatively rare, BHD should be considered as underlying cause, especially when there is a positive family history for pneumothorax, skin fibrofolliculomas or renal cell cancer. BHD patients are at increased risk for renal cell cancer and therefore diagnosis is important for the affected children and their family members. Therefore we suggest that a thorough family history, low dose chest CT (with the restraints of using $\mathrm{CT}$ scans in the paediatric population) and easy accessible genetic testing for BHD are important options for paediatric patients with (recurrent) SP should be performed, even when skin manifestation are absent. We also suggest more research is needed on the prevalence of BHD in the pediatric population with a history of (recurrent) SP.

\section{Consent}

Written informed consent was obtained from both patients for publication of this Case report and any accompanying images. Both patients were over the age of 18 when the manuscript was submitted to this journal.

\section{Ethics}

The retrospective data collected for this Case report was part of patient care and was performed in accordance with the Declaration of Helsinki. Therefore exemption was granted by our ethics committee. We obtained written informed consent from both patients for publication of this Case report and any accompanying images. Copy of written consent forms are added as additional supplement.

\section{Conclusions}

As SP in the paediatric population is relatively rare, BHD should be considered as underlying cause, especially when there is a positive family history for pneumothorax, skin fibrofolliculomas or renal cell cancer. BHD patients are at increased risk for renal cell cancer and therefore diagnosis is important for the affected children and their family members. Therefore we suggest that a thorough family history, low dose chest CT (with the restraints of using CT scans in the paediatric population) and easy accessible genetic testing for BHD are important options for paediatric patients with (recurrent) SP should be performed, even when skin manifestation are absent. We also suggest more research is needed on the prevalence of BHD in the pediatric population with a history of (recurrent) SP.

\section{Abbreviations}

BHD: Birt-Hogg-Dubé syndrome; FLCN: Folliculin; SP: Spontaneous pneumothorax; CT: Computed tomography; MRI: Magnetic resonance imaging; VATS: Video assisted thoracoscopic surgery; BTS: British thoracic society; LCH: Langerhans cell histiocytosis; LAM: Lymphangioleiomyomatosis; LIP: Lymphocytic interstitial pneumonia; LCDD: Light chain deposition disease; ACCP: American College of Chest Physicians; PSP: Primary spontaneous pneumothorax.

\section{Competing interests}

All authors have no conflicts of interest to disclose.

\section{Authors' contributions}

PCJ collected the data, provided a substantial contribution to conceptation, design and drafting/writing of the manuscript, gave final approval of the version to be published and agreed to be accountable for all aspects of the work. BEEMvandenB provided a substantial contribution to the drafting/ writing of the manuscript, reviewed and revised it critically, provided the clinical data of patient case 1 as attending pulmonologist, gave final approval of the version to be published and agreed to be accountable for all aspects of the work. JJPG provided the genetic testing and analysis on both patients. Provided a substantial contribution to review and revise the manuscript critically, gave final approval of the version to be published and agreed to be accountable for all aspects of the work. AFN provided a substantial contribution to review and revise the manuscript critically, supervised the analysis and interpretation of the clinical patients data, supervised as attending pediatrician, gave final approval of the version to be published and agreed to be accountable for all aspects of the work. JHTMvanW, provided a substantial contribution to review and revise the manuscript critically, provided and interpreted the thoracic imaging of both patients as attending radiologist, gave final approval of the version to be published and agreed to be accountable for all aspects of the work. MAP, provided a substantial contribution to review and revise the manuscript critically, provided the clinical data of patient case 1 and 2 as attending thoracic surgeon, gave final approval of the version to be published and agreed to be accountable for all aspects of the work. RJAvanM, provided a substantial contribution to review and revise the manuscript critically, gave final approval of the version to be published and agreed to be accountable for all aspects of the work. FHM, provided a substantial contribution to review and revise the manuscript critically provided the genetic testing on Folliculin of patient case 1 and 2, contributed as the attending clinical geneticist of both families, gave final approval of the version to be published and agreed to be accountable for all aspects of the work. PEP, provided a substantial contribution to conceptation, design and drafting/writing, contributed to review and revise the manuscript critically, contributed as attending pulmonologist of patient case 2, gave final approval of the version to be published and agreed to be accountable for all aspects of the work.

\section{Acknowledgements}

We thank both families with BHD syndrome for their cooperation. We thank dr. M.M. de Jong, Department of clinical genetics, University Medical Center Groningen and dr. E. Blom, Department of clinical genetics, Maastricht University Medical Center, for their contributions in providing a part of the patient data.

\section{Funding source}

No funding was secured for this study.

\section{Financial disclosure}

All authors have no financial relationships relevant to this article to disclose.

\section{Author details}

${ }^{1}$ Department of Pulmonary Diseases, VU University Medical Center, PO Box 7057, 1007, MB Amsterdam, The Netherlands. ${ }^{2}$ Department of Pulmonary Diseases, Catharina Hospital, Eindhoven, The Netherlands. ${ }^{3}$ Department of Clinical Genetics, VU University Medical Center, Amsterdam, The Netherlands. ${ }^{4}$ Department of Paediatrics, VU University Medical Center, Amsterdam, The Netherlands. ${ }^{5}$ Department of Radiology, VU University Medical Center, Amsterdam, The Netherlands. ${ }^{6}$ Department of Thoracic Surgery, VU University Medical Center, Amsterdam, The Netherlands. ${ }^{7}$ Department of Urology, VU University Medical Center, Amsterdam, The Netherlands. ${ }^{8}$ Family Cancer Clinic, Antoni van Leeuwenhoek, The Netherlands Cancer Institute, Amsterdam, The Netherlands. 
Received: 19 February 2014 Accepted: 27 June 2014

Published: 3 July 2014

\section{References}

1. Birt AR, Hogg GR, Dubé WJ: Hereditary multiple fibrofolliculomas with trichodiscomas and acrochordons. Arch Dermatol 1977, 133(12):1974-1977.

2. Healthcare Cost and Utilization Project (HCUP): Kids'Inpatient Database (KID). 1997, 2000, 2003, 2006. Available at: http://www.hcup-us.ahrq.gov/kidoverview.jsp.

3. Dotson K, Johnson LH: Pediatric spontaneous pneumothorax. Pediatr Emerg Care 2012, 28(7):715-721.

4. Zganjer M, Cizmic A, Pajic A, Cigit I, Zganjer V: Primary spontaneous pneumothorax in pediatric patients: our 7-year expercience. J Laparoendosc Adv Surg Tech A 2010, 20:195-198.

5. Robinson PD, Cooper P, Ranganathan SC: Evidence-based management of pediatric primary spontaneous pneumothorax. Paediatr Respir Rev 2009, 10(3):110-117.

6. Sahn SA, Heffner JE: Spontaneous pneumothorax. N Engl J Med 2000, 342(12):868-874

7. Bense L, Lewander R, Eklund G, Hedenstierna G, Wiman LG: Non-smoking, non-alpha 1-antitypsin deficiency-induced emphysema in non-smokers with healed spontaneous pneumothorax, identified by computed tomography of the lungs. Chest 1993, 103:433-438.

8. Smit HJ, Wienk MA, Schreurs AJ, Schramel FM, Postmus PE: Do bullae indicate a predisposition to recurrent pneumothorax? Br J Radiol 2000 73:356-359

9. O'Lone E, Elphick HE, Robinson PJ: Sponatneous pneumothorax in children: when is invasive treatment indicated? Pediatr Pulmonol 2008, 43(1):41-46.

10. Schramel FM, Postmus PE, Vanderschueren RG: Current aspects of spontaneous pneumothorax. Eur Respir J 1997, 10:1372-1379.

11. Wilcox DT, Glick PL, Karamanoukian HL, Allen JE, Azizkhan RG: Spontaneous pneumothorax: a single-institution: 12-year experience in patients under 16 years of age. J Pediatr Surg 1995, 30:1452-1454

12. Ouanes-Besbes L, Golli M, Knani J, Dachraoui F, Nciri N, El Atrous S, Gannouni A, Abroug F: Prediction of recurrent spontaneous pneumothorax: CT scan findings versus management features. Respir Med 2007, 101:230-236.

13. Ren HZ, Zhu CC, Yang C, Chen SL, Xie J, Hou YY, Xu ZF, Wang DJ, Mu DK, Ma DH, Wang Y, Ye MH, Ye ZR, Chen BF, Wang CG, Lin J, Qiao D, Yi L: Mutation analysis of the FLCN gene in Chinese patients with sporadic and familial associated isolated primary spontaneous pneumothorax. Clin Genet 2008, 74:178-183.

14. Johannesma PC, Menko FH, Reinhard R, van Waesberghe JHTM, van Moorselaar RJA, Starink TM, Postmus PE: Primary spontaneous pneumothorax: a pilot study on the frequency of FLCN mutation (Birt-Hogg-Dube Syndrome). Am J Respir Crit Care Med 2014, 189:A6417.

15. Bessis D, Giraud S, Richard S: A novel familial germline mutation in the initiator codon of the BHD gene in a patient with Birt-Hogg-Dubé syndrome. Br J Dermatol 2006, 155(5):1067-1069.

16. Gunji Y, Akiyoshi T, Sato T, Kurihara M, Tominaga S, Takahashi K, Seyama K: Mutations of the Birt Hogg Dube gene in patients with multiple lung cysts and recurrent pneumothorax. J Med Genet 2007, 44(9):588-593.

17. Houweling AC, Gijezen LM, Jonker MA, van Doorn MB, Oldenburg RA, van Spaendonck-Zwarts KY, Leter EM, van Os TA, van Grieken NC, Jaspars EH, de Jong MM, Bongers EM, Johannesma PC, Postmus PE, van Moorselaar RJ, van Waesberghe JH, Starink TM, van Steensel MA Gille JJ, Menko FH: Renal cancer and pneumothorax risk in Birt-Hogg-Dubé syndrome; an analysis of 115 FLCN mutation carriers from 35 BHD families. Br J Cancer 2011, 105(12):1912-1919.

18. Toro JR, Wei MH, Glenn GM, Weinreich M, Toure O, Vocke C, Turner M, Choyke P, Merino MJ, Pinto PA, Steinberg SM, Schmidt LS, Linehan WM: BHD mutations, clinical and molecular genetic investigations of Birt-Hogg-Dubé syndrome: a new series of 50 families and a review of published reports. J Med Genet 2008, 45:321-331.

19. Schmidt LS: Birt-Hogg-Dubé syndrome: from gene discovery to molecularly targeted therapies. Fam Cancer 2013, 12(3):357-364.

20. Menko FH, van Steensel MA, Giraud S, Friis-Hansen L, Richard S, Ungari S, Nordenskjöld M, Hansen TV, Solly J, Maher ER, European BHD Consortium: Birt-Hogg-Dubé syndrome: diagnosis and management. Lancet Oncol 2009, 10(12):1199-1206.

21. Clarke BE: Cystic lung disease. J Clin Pathol 2013, 66(10):904-908.
22. Johannesma PC, Thunnissen E, Postmus PE: Lung cysts as indicator for Birt-Hogg-Dubé. Lung 2014, 192(1):215-216.

23. Tobino K, Gunji Y, Kurihara M, Kunogi M, Koike K, Tomiyama N, Johkoh T, Kodama Y, Iwakami S, Kikkawa M, Takahashi K, Seyama K: Characteristics of pulmonary cysts in Birt-Hogg-Dubé syndrome: thin-section CT findings of the chest in 12 patients. Eur J Radiol 2011, 77:403-409.

24. Kumasaka T, Hayashi T, Mitani K, Kataoka H, Kikkawa M, Tobino K, Kobayashi E, Gunji Y, Kunogi M, Kurihara M, Seyama: Characterization of pulmonary cysts in Birt-Hogg-Dubé syndrome: histopathological and morphometric analysis of 229 pulmonary cysts from 50 unrelated patients. Histopathology 2014. Jan 7 (in press).

25. MacDuff A, Arnold A, Harvey J, BTS Pleural Disease Guideline Group: Management of spontaneous pneumothorax: British Thoracic Society pleural disease guideline 2010. Thorax 2010, 65:ii18-ii31.

doi:10.1186/1471-2431-14-171

Cite this article as: Johannesma et al:: Spontaneous pneumothorax as indicator for Birt-Hogg-Dubé syndrome in paediatric patients. BMC Pediatrics 2014 14:171.

\section{Submit your next manuscript to BioMed Central and take full advantage of:}

- Convenient online submission

- Thorough peer review

- No space constraints or color figure charges

- Immediate publication on acceptance

- Inclusion in PubMed, CAS, Scopus and Google Scholar

- Research which is freely available for redistribution

Submit your manuscript at www.biomedcentral.com/submit
C BioMed Central 